\title{
A Manutenção Predial nas Edificações Públicas, um Estudo sobre a Legislação
}

\section{The Building Maintenance in Public Buildings, a Study on the Legislation}

\author{
Paschoal Gavazza de Araújo Neto(paschoalgavazza@hotmail.com) \\ Universidade Federal de Mato Grosso - Faculdade de Arquitetura, Engenharia e Tecnologia \\ Mestrando em Engenharia de Edificações e Ambiental
}

Enviado, Aceito e Publicado em: Junho de 2015

\begin{abstract}
RESUMO: A manutenção predial compreende todas as ações que se realizam nos elementos construtivos, equipamentos e instalações que formam o conjunto de sistemas que proporcionarão segurança, habitabilidade e eficiência a uma edificação proveniente de um projeto em que a execução e os materiais empregados terão maior vida útil decorrente da maneira de utilização. As falhas de projeto significam que a falta de detalhamento, omissões e equívocos podem levar a escolhas erradas de material a ser empregado ou a técnicas construtivas que induzam ao erro de procedimento. A pesquisa tem o propósito de apontar os critérios para manutenção preventiva e preditiva e levantar ferramentas que mostrem que as falhas na execução são serviços em que o controle de qualidade não obteve rigor com omissões de especificações de projeto e o não cumprimento de normas estabelecidas. Falhas decorrentes de utilização são aquelas em que elementos construtivos que foram usados de forma errada a ponto de comprometer o desempenho ao longo do tempo. A relevância da pesquisa é a procura da metodologia que atinja um procedimento onde a manutenção corretiva será transformada pelos gestores de manutenção no objetivo da administração superior, com o intuito de que a manutenção preditiva atue na redução dos custos, no aumento do conforto térmico, lumínico e ambiental para os usuários e resulte na diminuição dos desgastes naturais e nas deteriorações prematuras.
\end{abstract}

Palavras-chave: Manutenção Preventiva e Preditiva. Edificação Pública. Metodologia.

\begin{abstract}
The building maintenance includes all actions that take place in the constructive elements, equipment and facilities that form the set of systems that provide safety, livability and efficiency of a building from a project in which the execution and materials employed have higher life useful way. As due to design flaws mean that the detailing, omissions and mistakes can lead to wrong choices of material to be used or construction techniques that lead to a procedure error. The research aims to point out the criteria for preventive and predictive maintenance and choosing tools that show the flaws in execution are services where the quality control is not got rigor with omissions of design specifications and failure to comply with established standards. The failure due to use are those in which building elements that have been misused to the point of compromising performance over time. The relevance of the research is the search methodology that achieves a procedure where corrective maintenance will be transformed by the maintenance managers in the goal of upper management in order that the predictive maintenance act on reducing costs, increasing thermal comfort, luminal and environment for users and result in a decrease in the natural wear and premature deterioration.
\end{abstract}

Keywords: Preventive and Predictive Maintenance. Public building. Methodology.

\section{INTRODUÇÃO}

A manutenção predial em edificações públicas é realizada por meio de procedimentos de vistorias, limpezas e reparos em componentes e sistemas construtivos. A verificação do envelhecimento das edificações em geral, é constatado em virtude da verticalização dos grandes centros urbanos do país, entre as décadas de 50 e 70 segundo Pini (2011).
A escassez de novas áreas para construções novas e a limitação geográfica tem colaborado para a redução da expansão das metrópoles e o aumento do custo do metro quadrado para construção em todo país e principalmente nas capitais.

A manutenção predial deverá passar por um processo de conscientização pelos detentores do patrimônio deixando de lado a forma do improviso e a falta de planejamento, rigor técnico e o uso da informalidade no 
tratamento da manutenção predial e iniciar a elaboração de um plano de manutenção predial que atenda à gestão de manutenção preditiva que implique na inspeção predial, na análise de desempenho, eficiência ambiental, durabilidade dos materiais empregados e dos sistemas construtivos.

A busca para a redução de acidentes e prejuízos com a falta de planejamento na manutenção predial deverá ser priorizada pelos gestores do patrimônio público ou privado considerando que os riscos com o aumento dos custos na manutenção, a insegurança do usuário, a interrupção das operações da edificação e a desvalorização da edificação poderá ser contestada com o rigor da engenharia no desenvolvimento do ciclo de vida da edificação, segundo Pini (2011).

\section{JUSTIFICATIVAS E OBJETIVO}

\section{Justificativas}

A vida útil e os níveis de desempenho dos sistemas que compõem uma edificação são fatores que justificam o investimento na aplicação de recursos públicos para a manutenção predial. O aumento do conforto ambiental e confiabilidade do usuário aliado à correta utilização dos espaços físicos proporcionará a diminuição dos desgastes naturais e deteriorações prematuras. A redução de custos com a racionalização na compra de diversos materiais contribuirá para a redução dos impactos da agressão ao meio ambiente.

A durabilidade das edificações está ligada diretamente a rotina de manutenção e custos, impostos pela forma de utilização do usuário. Observa-se em geral que gestores de manutenção predial devem conscientizar os administradores da necessidade de aplicar uma manutenção planejada, organizada com funcionalidade e especializada. Os recursos a serem programados pelos administradores devem ser obrigatoriamente destinados à manutenção preventiva e também a corretiva de modo a preservar o patrimônio público institucional.

Xavier (1998) aponta como atividades de manutenção a resolução dos problemas relacionados com a alta taxa de retrabalho; a falta de equipes qualificadas; a falta de estoques para equipamentos e peças de reposição e também a falta de banco de dados e planejamento prévio.

As atividades da manutenção predial têm a característica da complexidade, os sistemas e subsistemas que compõem as edificações institucionais são estruturas compostas por diversos elementos construtivos tais como: a fundação, a estrutura, o sistema de vedação, os revestimentos, as esquadrias, e as impermeabilizações, como também, as instalações hidráulicas e elétricas, o sistema de esgoto, incêndio, telefonia são todos os elementos que formam a estrutura física de uma edificação.

As dificuldades para a execução das ações de manutenção ocorrem por motivos diversos, inclusive por motivação cultural e de aceitação por parte dos próprios usuários, quando postergam o início dos serviços a serem realizados.

\section{Objetivo}

Avaliar os procedimentos gerais de manutenção em prédios públicos e identificar os requisitos e critérios para a manutenção preventiva das edificações públicas por meio dos os elementos necessários para a implantação do plano de manutenção predial.

\section{REVISÃO DA LITERATURA}

A revisão da literatura aborda itens como: o primeiro tema, associado à importância da elaboração dos projetos de arquitetura; o segundo tema versa sobre as características de uma obra pública; o terceiro tema o ciclo devida de uma edificação; o quarto tema descreve a manutenção preventiva e corretiva; o quinto refere-se a manutenção preditiva; o sexto tema trata da 
inspeção predial; o sétimo faz referência a norma de desempenho ABNT NBR 15575:2013 e por fim o oitavo tema aborda o processo de modernização das edificações.

\section{A Importância na elaboração dos projetos de Arquitetura}

Conforme a ABNT NBR 9050:2012 Acessibilidade a edificações, mobiliário, espaços e equipamentos - "a elaboração de projetos de arquitetura, construção e reformas por parte de órgãos, da administração pública tem como obrigação atender às normas brasileiras de acessibilidade, edificações, mobiliário, espaços e equipamentos urbanos".

Os trabalhos devem ser rigorosamente realizados em obediência às diversas etapas de projeto que são estabelecidas nas Práticas de Projeto, Construção e Manutenção de Edifícios Públicos Federais, de modo a evoluírem gradual e continuamente em direção aos objetivos estabelecidos pela instituição e reduzirem os riscos de perdas e de ter que refazer os serviços.

Os procedimentos delineados acima indicam a forma do tratamento a que a administração pública atuará para que as etapas sejam cumpridas de maneira que os objetivos sejam alcançados dentro dos prazos estabelecidos em geral pelo Edital de Licitação.

É importante destacar o autor do projeto que deve ser o principal agente para compatibilizar os projetos desenvolvidos que devem atender normas de desempenho das edificações em áreas de estrutura, vedações, instalações elétricas, hidráulicas e esgoto, conforto térmico e lumínico, assim como outros projetos complementares, visando a racionalidade e soluções que priorizem um aumento da vida útil da edificação.

Os projetistas devem contemplar tecnologias e equipamentos que visam adequar o projeto às características do local e ter como resultado final um produto arquitetônico que teve em consideração diferentes níveis de elaboração.

Os projetos de construção, complementação, reformas ou ampliação de uma edificação devem atender de três níveis de procedimentos: estudo preliminar, projeto básico e projeto executivo. Essas etapas tem início no plano de necessidades que define as características das edificações.

\section{O Estudo Preliminar}

Visa à análise e escolha da solução que melhor responda ao programa de necessidades, sob os aspectos legais, técnicos, econômicos e ambientais do interesse da administração pública. Além de estudos e desenhos que assegurem a viabilidade técnica e o adequado tratamento do impacto ambiental, o Estudo Preliminar deve apresentar um relatório justificativo, contendo a descrição e avaliação da alternativa selecionada, as suas características principais, os critérios, índices e parâmetros utilizados e demais demandas a serem atendidas.

\section{O Projeto Básico}

É o elemento mais importante para a execução de uma obra pública por ser o conjunto de elementos que define a obra, o serviço ou o complexo de obras e serviços que compõem o empreendimento, de tal modo que suas características básicas e desempenho almejado estejam perfeitamente definidos, possibilitando a estimativa de seu custo e prazo de execução.

\section{O Projeto Executivo}

Deverá demonstrar a viabilidade técnica e a avaliação do impacto ambiental, a possibilidade da avaliação do custo dos serviços e obras, objeto da Lei de Licitação, bem como, estabelecendo os métodos construtivos, detalhados e prazos de execução corretamente definidos.

\section{A Obra Pública}

A obra pública tem a finalidade de atender os interesses gerais da sociedade. A contratação por órgão ou entidade da 
Administração Direta ou Indireta no âmbito federal, estadual ou municipal estabelece a responsabilidade delegada a um órgão gestor para a construção, reforma fabricação, recuperação ou ampliação de um bem público.

O planejamento de uma obra significa definir o que fazer, quando fazer, como fazer, onde fazer, a que custo se espera fazer, estabelecendo seus mecanismos de controle. Cada uma das etapas de execução de uma obra deve ser adequadamente estudada, planejada e subdividida de forma a cumprir, não somente em seus aspectos legais e formais, mas de modo a resultar em uma obra de boa qualidade, segura, adequada à finalidade a que se destina e a um preço compatível.

Genericamente será tratada por obra pública a construção, reforma, fabricação, recuperação ou ampliação e os serviços de engenharia realizados por execução direta ou indireta. A execução de obra pública e todos os demais atos da administração pública devem atender aos princípios da legalidade, legitimidade, eficiência, e economicidade, princípios inscritos na Constituição Federal.

A estruturação de uma obra pública a ser executada nasce de um programa de necessidades no qual haverá definições quanto ao destino da edificação, as dimensões aproximadas e o padrão de acabamento a que se pretende dar ao projeto. Nesta fase é elaborada a estimativa de custos por meio do orçamento estimativo. As fases seguintes são a escolha do terreno, o estudo de impacto ambiental, a viabilidade técnica e econômica para a escolha da melhor opção que responda ao programa de necessidades elaborado. $\mathrm{O}$ Plano Diretor, por exemplo, identifica a estrutura física disponível para a realização das atividades no Campus Universitário, seus problemas e potencialidades. A partir deste levantamento devem-se estabelecer diretrizes para as construções Campus.

É função do plano diretor estabelecer o planejamento o uso do solo (setorização, implantação de futuras edificações, centros de convivência e áreas livres), sistema viário (projeto urbanístico com anéis viários e conexão com a cidade), meio ambiente (preservação e uso racional dos recursos naturais) e infraestrutura (esgoto, fornecimento de água, drenagem pluvial, energia-elétrica, centro de processamento de dados).

\section{Avaliação da Manutenção Predial}

Pujadas (2011) afirma que "a avaliação da manutenção predial está na identificação das anomalias que apresentam melhoria contínua e na observação das necessidades de mudanças de procedimento devido à perda de desempenho".

A avaliação da manutenção predial devem seguir as seguintes fases de inspeção; identificação do tipo de estratégia de manutenção; verificação da coerência da estratégia identificada com as expectativas dos usuários; execução da inspeção predial para verificação de não conformidades técnicas de utilização e de manutenção; analise da documentação referente à edificação para complementação de dados fornecidos pela inspeção e identificação de falhas em contratos de manutenção com empresas terceirizadas; avaliação da equipe de manutenção quanto a sua formação, dimensionamento e capacidade de cumprir as ações determinadas; avaliação dos custos da manutenção e por fim avaliação da qualidade da manutenção empregada.

\section{O Alcance da Manutenção Predial}

A atividade de manutenção predial tem impacto direto no serviço público prestado e nas condições de segurança, uso e conforto por parte do usuário.

A manutenção é definida na ABNT NBR 15575 - Coletânea de Normas Técnicas Edificações Habitacionais - Desempenho, como o conjunto de atividades a serem realizadas e respectivos recursos para conservar uma edificação. Recuperar a capacidade funcional da edificação e de seus sistemas constituintes de modo atender às 
necessidades e segurança dos seus usuários, também, por ser o foco da manutenção.

A engenharia diagnóstica é apresentada por (CARVALHO; RAGAZZI; PINI, 2011) pelos autores como o processo consubstanciado em diferentes etapas, com vistas às técnicas em produtividade e inovação em abrangência com o planejamento, o projeto, a execução e por fim a forma de utilização por parte dos usuários.

\section{Banco de Dados}

A elaboração de um banco de dados torna-se importante para o planejamento do processo de sistematização do programa de manutenção predial. A relação custo $\mathrm{X}$ benefício deve ser adotada no planejamento da manutenção preventiva. Dificuldades de gestão pública conduzem a edificações pouco preservadas e depreciadas ao longo do tempo, sendo desprezadas pelos usuários. O plano da manutenção predial deverá promover mudanças na cultura e atividades das pessoas que fazem esse tipo de serviço diariamente, atendendo suas necessidades de maneira satisfatória.

\section{Ciclo de Vida}

O ciclo de vida geral de uma edificação apresenta vários fatores de degradação que tem início geralmente na fase elaboração de projeto com informações deficientes ou alterações durante a execução, incompatibilidades de especialidades, especificações inadequadas de materiais e falta de considerar aspectos da manutenção.

A fase de construção poderá apresentar degradação por informação equivocada de serviços a serem realizados, supervisão ineficiente, prazos de execução fora da realidade da obra e mão-de-obra não qualificada com também apresentar os seguintes agentes de degradação: agentes mecânicos, eletromagnéticos, agentes químicos, biológicos e climatológicos.

\section{Manutenção Preventiva e Corretiva}

Antonioli (2011) afirma que "o planejamento dos serviços de manutenção predial pode ser dividido em preventivos e corretivos". A primeira reduz custos e a segunda apresenta melhores condições de aquisição de materiais e serviços por meio de negociações efetuadas com maior tempo disponível para avaliação e decisão de compra.

Segundo o Manual de Obras Públicas Edificações - Práticas da SEAP - Secretaria de Estado da Administração e do Patrimônio, os conceitos e terminologias para as práticas de manutenção predial são definidos como a seguir:

- Componente: composição, associação, fixação ou aplicação de materiais e equipamentos na edifícação.

- Desempenho técnico: comportamento de um componente ou sistema da edificação submetido ao uso através do tempo.

- Conservação: atividade técnica e administrativa com a característica de preservar o desempenho técnico dos componentes da edificação.

- Manutenção: atividade técnica e administrativa destinada a preservação das características de desempenho técnico dos componentes ou sistemas da edificação, cujo o funcionamento depende de dispositivos mecânicos, hidráulicos, elétricos e eletromecânico.

- Manutenção corretiva: atividade de manutenção executada após a ocorrência de falha ou de desempenho insuficiente dos componentes da edificação.

- Manutenção preventiva: atividade de manutenção executada antes da ocorrência de falha ou de desempenho insuficiente dos componentes da edificação.

- Plano de manutenção: conjunto de inspeções periódicas destinadas a evitar a ocorrência de falhas ou perda de desempenho nos componentes da edificação, definidas em função das características dos componentes da edificação e orientação técnica dos fabricantes ou fornecedores. 


\section{Manutenção Preditiva}

A automação do plano de manutenção acarretará em procedimentos com capacidade de produzir uma tecnologia para emissão de ordens de inspeção, relatório de campo, orçamento e programação da manutenção predial, identificação de fornecedores, execução de procedimentos de compras, emissão de ordem de serviço, receberem relatórios da fiscalização e realimentar o ciclo de manutenção.

A manutenção preditiva tem como característica preponderante o início do ciclo pela inspeção técnica e que difere da manutenção corretiva que se inicia a partir do registro efetuado pelo usuário. A metodologia para a manutenção preditiva tem conteúdos técnicos que abrangem dados como: identificação, especificações, consumos e produtividade.

A tecnologia da gestão de manutenção permite a elaboração de planejamento nas ações de inspeção, possibilitando quantificar, orçar, comprar, contratar, executar e atender as demandas dos usuários. A técnica de gestão em que a engenharia e a informática se completam no objetivo de dar o suporte necessário aos profissionais que atuam nesta área oferecem condições de antecipar o surgimento determinadas anomalias e com isso exercer a administração efetiva de forma contínua considerando custos e demais elementos de controle da execução, realimentando do ciclo de manutenção predial.

A programação preditiva por meio do levantamento permite a elaboração da base de dados que definirá a frequência das inspeções técnicas, vida útil, e garantias dos serviços de manutenção. Segundo Antonioli (2011), "a manutenção predial preditiva, não impede a necessidade de intervenções corretivas, porem a atuação será menor e com menores impactos nos custos". A qualidade do processo de planejamento poderá se atingida por meio de um procedimento citado por Antonioli (2011), como "Avaliação de Condições" (Conditioning Assessment) sistema utilizado pelo mercado para uma auditoria completa da edificação a ser analisada.

Deste modo o levantamento dos custos das não conformidades encontradas, são detalhados e descritos com diagnósticos das correções a serem executadas e armazenadas em banco de dados. Entre as informações alimentam o sistema de planejamento de manutenção a ser elaborado com planos de execução que abrangerão planejamento de curto, médio e longo prazo.

\section{A Importância da Inspeção Predial}

Fornece diferentes informações que possibilita a caracterização da patologia identificada com detalhe. $\mathrm{O}$ estado da patologia identificada, às condições de utilização, ás condições de manutenção adotadas, as condições de operação, o estado de urgência devem ser considerados para evitar o seu desdobramento em outras manifestações patológicas.

Os relatórios de inspeção técnica fornecem à gestão de manutenção condições de organizar e estimar custos para às intervenções necessárias considerando o grau de criticidade avaliados nos relatórios. Os critérios de hierarquização serão estabelecidos por combinações das matrizes custos por criticidade.

A prioridade são as ocorrências emergenciais, em seguida o confronto entre custo e criticidade. Estes os procedimentos possibilitam a elaboração de uma rotina no planejamento da manutenção predial. A base são os relatórios de inspeção técnicas que de forma completa forneceram aos gestores informações suficientes e necessárias para a tomada de decisão e hierarquização das ações. Segundo Pujadas (2013), estudo sobre acidentes ocorridos em edificações com mais de trinta anos, com base em dados de conhecimento comum, publicados pela imprensa, e colaboração do Corpo de Bombeiros do Estado de São Paulo, Figura 1. 
Figura 1 - Falhas de manutenção predial e patologias

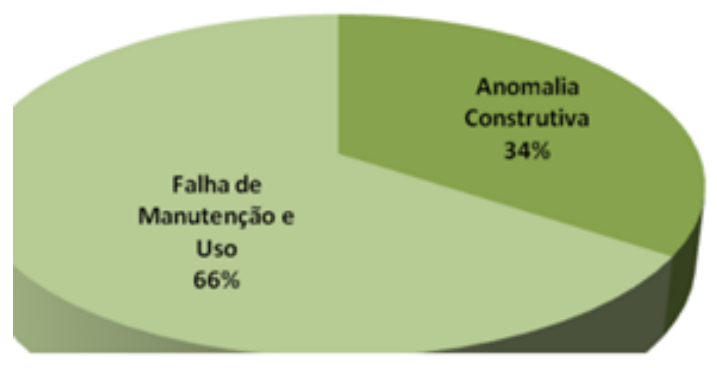

Fonte: IBAPE/SP (2012/2013)

A inspeção em edificações pode ser considerada como o check-up da saúde predial, uma visão da manutenção é a que permita conhecer detalhadamente as condições do edifício, oferecendo meios para preservar seu desempenho original e sempre aprimorar sua qualidade.

O conceito de inspeção predial é estabelecido pela norma do IBAPE/SP como "a análise isolada ou combinada das condições técnicas, de uso e de manutenção da edificação".

Outras definições de normas são um complemento do conceito apresentado, como a "avaliação do estado da edificação e de suas partes constituintes, realizada para orientar as atividades de manutenção" da NBR 5674, ou o conceito da NBR 15575-1 que estabelece a manutenção como, "verificação, através de metodologia técnica, das condições de uso e de manutenção preventiva e corretiva da edificação".

O desenvolvimento de novas normas técnicas, tais como a norma de desempenho, a do manual de uso, a própria norma de manutenção e a prática da inspeção predial em grandes e diversas edificações, revelaram a necessidade de maior amplitude do escopo original da inspeção predial, para se adequar aos enfoques da sustentabilidade, desempenho, durabilidade e novas tecnologias.

Falhas de construção e manutenção predial inadequada são causadoras de mortes e prejuízos injustificáveis. O envelhecimento e consequentemente desvalorização das edificações, causam desabamentos, incêndios, quedas de marquise e fachadas, vazamentos, infiltrações e outros tipos de patologias causadas por falta de manutenção e descuidos que podem ser evitados com medidas preventivas e planejamento.

\section{Laudo de Inspeção}

O laudo de inspeção predial é o instrumento inicial para a implantação do plano de manutenção com visão no aprimoramento técnico da edificação.

As novas recomendações das normas revisadas da ABNT para a construção civil segundo Gomide (2013) impõem maior amplitude de avaliações da inspeção predial tradicional, determinando a necessidade de notas técnicas no desempenho/degradação, além de outras medidas.

As recomendações podem ser resumidas seguindo a norma da ABNT NBR 5674 (ago.2012) - Manutenção de edificações Requisitos para o sistema de gestão de manutenção - que identifica os meios para a preservação das características originais da edificação e conservação do desempenho decorrente do uso contínuo de seus sistemas, elementos e componentes.

\section{Norma de desempenho ABNT NBR 15575:2013}

A norma busca parâmetros para avaliação e análise técnica das condições de uso, análise técnica da manutenção preventiva, análise técnica da manutenção corretiva, avaliação das condições de conservação da edificação, atestar, ou não, a suficiência dos procedimentos de manutenção predial e fornecer subsídios para orientar o plano e programa de manutenção.

Com tais exigências ficou imperativo, a mudança do "status quo", visando desenvolvimento de ferramentas como a metodologia para a inspeção predial, inclusive acrescentado notas técnicas ao desempenho e segurança do usuário e medidas normativas devido aos novos projetos de lei, legislações estaduais e municipais com visão no aprimoramento da execução dos serviços originados da manutenção predial para 
devolução do desempenho da edificação às características iniciais.

\section{Processo de Modernização}

As edificações da última década de países do primeiro mundo adotam o comissionamento como parte integrante de projetos e contratos de construção civil, segundo Saes (2011), para novas edificações ou retrofit das edificações existentes.

A complexidade e sofisticação dos sistemas construtivos atuais com a implantação de novas tecnologias em que essa abordagem assegura atendimento às especificações e a requisitos de projeto com verificação de sistemas e subsistemas construtivos em que a garantia do desempenho operacional por meio da documentação detalhada e gerenciamento com eficiência durante o ciclo de vida.

O comissionamento é um processo sistemático com o objetivo de assegurar o desempenho de uma edificação com total às premissas estabelecidas nos projetos e seus sistemas construtivos prediais e a documentação contratual, execução e necessidades para operação determinadas pelo cliente final conforme afirma Saes (2011), citando (Building Commissioning Association, EUA, 2004).

Os sistemas construtivos prediais estão em cada vez mais complexos e com o desenvolvimento de inovações tecnológicas objetivando a conservação o desempenho e valorização da edificação segundo Saes (2011), que aponta os elementos do comissionamento, como: a conservação de insumos (água, energia, etc.), os avanços tecnológicos em equipamentos de escritórios, o sistema de controle do ar interno da edificação, os avanços nos sistemas de telefonia, imagens, vídeo, comunicação de dados e informações, os ambientes de trabalho com segurança, os controles relativos ao conforto dos ambientes internos e a complexidade dos sistemas de automação predial.

\section{CONSIDERAÇÕES FINAIS}

A legislação encontrada na pesquisa, referente aos serviços originados pela degradação natural dos sistemas e componentes de uma edificação ou por ações efetivadas pelos usuários quando do setor público, data de julho de 1997 pela portaria ${ }^{\circ}$ 2.296 do Departamento de Serviços Gerais DSG do Ministério de Estado da Administração Federal e Reforma do Estado, no qual no Art. $1^{\circ}$ estabelece Práticas de Projeto, Construção e Manutenção de Edifícios Públicos Federal, onde estão definidas as terminologias, condições gerais, normas e práticas complementares, estabelecendo o Caderno de encargos com as diretrizes gerais para a elaboração, garantia de qualidade a ser adotada na execução de serviços de manutenção de uma edificação ou conjunto de edificações, a fiscalização dos serviços e o recebimento e por fim o pagamento do serviço concluído.

\section{CONCLUSÕES}

As referências encontradas permitem concluir que a legislação em vigor, é adequada aos procedimentos que visam a manutenção predial em edificações públicas, privadas, habitacionais ou comerciais.

O questionamento a ser feito é se gestores da administração federal na área de manutenção predial, utilizam os procedimentos definidos pela legislação e normas existentes e, se os recursos destinados nos orçamentos dos órgãos governamentais são suficientes para a implantação dos procedimentos necessários à manutenção predial. 


\section{REFERÊNCIAS BIBLIOGRÁFICAS}

ANTONIOLI, P. E. Planejamento de manutenção. São Paulo: Pini. 2011.

ASSOCIAÇÃO BRASILEIRA DE NORMAS TÉCNICAS. NBR $\mathbf{1 5 5 7 5}$ (jul.2013) - Desempenho de edificações habitacionais. Rio de Janeiro. 2013.

ASSOCIAÇÃO BRASILEIRA DE NORMAS TÉCNICAS. NBR $\mathbf{5 6 7 4}$ (ago.2012) - Manutenção de edificações Requisitos para o sistema de gestão de manutenção. Rio de Janeiro. 2012.

ASSOCIAÇÃO BRASILEIRA DE NORMAS TÉCNICAS. NBR 9050 (ago.2012) - Acessibilidade a edificações, mobiliário, espaços e equipamentos urbanos. Rio de Janeiro. 2012.

PUJADAS, F. Z. A. Inspeção Predial: A saúde dos edifícios. São Paulo. 2011.

XAVIER, J.N. Manutenção Classe Mundial. 1998. Disponível em: < http://www.tecem.com.br/downloads/manuten cao.pdf $>$ Acesso em: 23 de novembro de 2013.

CARVALHO, Luiz Freire de. Manutenção preditiva em busca da metodologia. In: Pini, Mario Sergio et al. Manutenção Predial. São Paulo: 2011. P. 26-28.

SAES, Francisco. Comissionamento de edificações. In: Pini, Mario Sergio et al. Manutenção Predial. São Paulo: 2011. P. 29-33.

GOMIDE, Tito Lívio Ferreira. Manutenção predial e avaliação imobiliária. In: Pini, Mario Sergio et al. Manutenção Predial. São Paulo: 2011. P. 29-33.
SIQUEIRA, Ailton Pessoa at al. Inspeção predial. 3. ed. São Paulo: Liv. e Ed. Universitária de Direito. 2012.

SECRETARIA DE ESTADO DA ADMINISTRAÇÃO E DO PATRIMÔNIO SEAP.Manual de Obras Públicas Edificações Práticas da SEAP. Disponível em

http://www.comprasgovernamentais.gov.br/ar quivos/manuais/manual_manutencao.pdf $>$. Acesso em 06 jun. 2015. 